\title{
lingua Franca
}

\section{Jurnal Bahasa dan Sastra}

Pemerolehan Bahasa Arab Anak Usia 4 s.d. 8 Tahun di Pondok Modern Arrisalah Ponorogo

\section{Arabic Language Acquisition for Children Age 4 s.d. 8 Years at Pondok Modern Arrisalah Ponorogo}

\author{
Melani Candra Fransika Adiluhung ${ }^{1}$, Vivia Salma Azzahro², \\ Melani Widya Nafi'atus ${ }^{3}$, Lisma Meilia Wijayanti ${ }^{4}$ \\ ${ }^{1234}$ Institut Agama Islam Sunan Giri; Ponorogo; Indonesia \\ ${ }^{1}$ E-mail: melanicandra18@gmail.com
}

\section{Abstrak}

Penelitian ini bertujuan untuk mendeskripsikan pemerolehan Bahasa Arab anak usia 4 s.d. 8 tahun di Pondok Arrisalah Ponorogo. Jenis penelitian ini adalah kualitatif dengan pendekatan deskriptif kualitatif. Objek kajian dalam penelitian ini dilakukan terhadap anak-anak usia 4 s.d. 8 tahun tingkat PIAUD sampai SD di Pondok Modern Arrisalah Ponorogo. Tujuannya agar pengawasan terhadap perkembangan bahasa arab terus berjalan, sehingga mampu meningkatkan kepandaian anak dalam berbahasa Arab. Metode pengumpulan data dilakukan dengan teknik rekam, simak, dan catat. Hasil penelitian menunjukkan bahwa pemerolehan Bahasa Arab anak usia 4 s.d 8 tahun di Pondok Arrisalah Ponorogo belum sepenuhnya sempura. Hal itu karena masih banyak yang perlu diperbaiki, seperti pelafalan bunyi yang salah, penambahan bunyi yang tidak perlu, dan pengucapan panjang pendeknya huruf yang masih kurang tepat.

Kata Kunci; Arrisalah; Bahasa Kedua; Kesalahan Berbahasa; Pemerolehan Bahasa Arab Anak

\section{Abstract}

This study aims to describe the acquisition of Arabic for children aged 4 to $d$. eight years at Pondok Arrisalah Ponorogo. This type of research is qualitative with a qualitative descriptive approach. The study's object was conducted on children aged 4 to $d$. eight years from PIAUD to SD at Pondok Modern Arrisalah Ponorogo. The goal is that supervision of the development of the Arabic language continues to improve children's intelligence in Arabic. The data collection method is recording, listening, and taking notes. The results showed that the acquisition of Arabic for children aged 4 to 8 years at Pondok Arrisalah Ponorogo was not yet perfect. This is because many things still need to be improved, such as the pronunciation of wrong sounds, the addition of unnecessary sounds, and the articulation of long and short letters that are still not quite right.

Keywords; Arrisalah; Children's Arabic Acquisition; Children's Language Errors; Second Language, 
(C) 2022 by the authors. Submitted for possible open access publication under the terms and conditions of the Creative Commons Attribution-NonCommercial 4.0 International License (CC BY NC) license (https://creativecommons.org/licenses/by-nc/4.0/).

\section{PENDAHULUAN}

Bahasa dapat diartikan dari berbagai macam sudut pandang. Bahasa bisa didefinisikan sebagai perkataan yang diucapkan maupun ditulis, ada pula yang menyebutkan bahwa bahasa merupakan sebuah alat untuk berkomunikasi antar manusia, dan ada pula yang mengatakan bahwa bahasa adalah jenis-jenis kata, baik kata kerja, kata sifat, ungkapan, kalimat, dan lain sebagainya yang dipelajari di sekolah. Bahasa hanya sebagai kumpulan kata, kaidah, ataupun sebuah peraturan (Izan, 2011).

Beberapa pertanyaan sering muncul terhadap kajian mengenai pemerolehan bahasa. Misalnya, bagaimanakah pengetahuan terkait bahasa muncul pada usia anak-anak? Bagaimana bahasa pada anak bisa berkembang? Bagaimana proses pemerolehannya? Apa dasarnya? dan lain sebagaianya. Pertanyaan-pertanyaan tersebut menjadi milequestions pada teori pemerolehan bahasa terhadap pemerolehan bahasa pertama, maupun pemerolehan bahasa asing (bahasa kedua). Teori akulturasi menyampaikan bahwa proses pemerolehan bahasa menjadi salah satu aspek penting dalam pemerolehan bahasa asing atau bahasa kedua (Tarigan, 2011). Akulturasi dapat ditentukan melalui faktor sosial, faktor jarak sosial, dan faktor psikis terhadap budaya sasaran dalam akulturasi pemerolehan bahasa (Syahid, 2014). Misalnya, seperti orang Indonesia yang memperoleh Bahasa Arab yang dipengaruhi oleh sosial dan psikisnya terhadap budaya Arab itu sendiri. Kajian-kajian terkait pemerolehan bahasa asing pada siswa non-native di Indonesia sangat penting untuk diketahui karena akan menjawab pertanyaan terkait bagaimana orang Indonesia mampu memahami bahasa dan kaidah-kaidah bahasa asing tersebut.

Pemerolehan bahasa pada anak-anak biasanya terjadi antara usia nol sampai lima tahun. Proses tersebut terjadi secara berurutan, mulai dari bunyi-bunyi yang belum memiliki makna, hingga sepatah dua patah kata yang mulai jelas. Pada tahapan tersebut seorang ibu harus memperkenalkan segala sesuatu yang ada di dalam atau sekitar lingkungannya. Seorang anak yang baru dilahirkan sebenarnya belum memiliki apa-apa, dalam arti bahwa anak yang baru dilahirkan ibarat selembar kertas putih yang belum dituliskan apapun. Namun, setelah lama berada dalam lingkungannya, terutama dalam lingkungan keluarga barulah ia mendapat sesuatu dari apa yang dia dengar (simak). Mereka (golden age) adalah usia yg sangat tepat untuk belajar dan berkembang.

Setelah memperoleh bahasa pertama, umumnya anak akan memperoleh bahasa keduanya melalui lembaga formal, seperti sekolah, lembaga pelatihan, dan lain sebagainya. Pembelajaran bahasa kedua merupakan sebuah proses belajar tentang bagaimanakah bahasa asing atau bahasa kedua itu dipelajari. Bahasa tidak dibatasi atas bahasa asing daerah ataupun nasional. Kemudian ada juga pendekatan-pendekatan terkait hal-hal yang berkaitan dengan linguistik yang memandang bahwa terdapat faktor internal yang memengaruhi 
Vol. 1, No. 1 (2022)

DOI; https://doi.org/10.37680/linguafranca.v1i1.1220

seseorang dalam mempelajari bahasa keduanya atau biasa disebut dengan analisis error (Fatmawati, 2015).

Penguasaan maupun pemerolehan bahasa anak menjadi hal yang menarik untuk dipelajari dan diteliti secara menyeluruh. Proses pemerolehan dan penguasaan bahasa pada anak juga telah dikemukakan oleh para peneliti. Tanpa disadari bahwa system linguistic mampu dikuasi oleh seorang anak tanpa melalui pengajaran secara formal.

Pemerolehan bahsa yang dialami oleh seorang anak akan berkaitan dengan keuniversalan bahasa. Hal tersebut berarti bahwa terdapat elemen bahasa yang berurutan memiliki sifat universal, absolut, implikasional, dan statistical. Terutama pada bagian pemerolehan fonologi yang memiliki tingkat absolut yang sangat tinggi. Sebuah bunyi tidak akan mampu dikuasi oleh anak sebelum adanya bunyi-bunyi lainnya. Sedangkan bagian sintaksis dan semantik tingkat keuniversalannya juga sangat beragam.

Terdapat beberapa hipotesis yang dikaji oleh ahli bahasa yang berkaitan dengan pemerolehan bahasa. Pertama, hipotesis Nurani yang menunjukkan hasil observasi tentang proses pemerolehan bahasa (Chaer, 2003). Kesimpulan dari hipotesis ini adalah bahwa manusia dilahirkan dengan indera yang mampu berfungsi untuk berbahasa secara mudah dan cepat. Namun pandangan ini sukar untuk dibuktikan, sehingga disebut dengan hipotesis Nurani (Wiziack \& dos Santos, 2021).

Kedua, hipotesisi Tabularasa. Seorang bayi diibaratkan sebagai kertas kosong yang nantinya diisi oleh pengalam selama dia hidup. John Lock seorang tokoh empirisme menjadi pengemuka hipotesis ini, kemudian dikembangkan oleh John Watson tokoh behaviorisme. Dalam hipotesis Tabularasa, hal-hal yang berkaitan dengan bahasa adalah hasil dari integrasi linguistik yang terdiri dari stimulus dan respon. Bagian dari respon seperti manda, echotics, tacts, textuals, dan intra verbal operant. Ilustrasi Jack and Jill dikenalkan oleh Bloomdield. Namun, hipotesis ini belum mampu menjelaskan terkait kompetensi dalam bidang linguistik anak yang telah disimpan di dalam otak dapat digunakan untuk memproduksi kalimat baru yang belum pernah didengar oleh si anak (Chaer, 2003). Hal tersebut kemudian menjadi salah satu kelemahan dalam hipotesis Tabularasa.

Ketiga, hipotesis Kesemestaan Kognitif. Hipotesis ini pertama kali dikenalkan oleh Piaget. Dalam hipotesisinya menyatakan bahwa bahasa didapatkan melalui struktur kognitif deriamotor saat proses interaksi dilakukan dengan sesama manusia maupun benda di sekitarnya. Anak hanya mempu memproduksi bunyi abstrak yang menyatakan rasa sakit, lapar, atau tidak nyaman pada usia 0-2 bulan. Meskipun bunyi abstrak itu belum memiliki makna, namun bunyi yang diproduksi tersbut menjadi bahan untuk bunyi selanjutnya.

Anak akan mengeluarkan bunyi vokal dengan campuran bunyi konsonan pada usia 2 sampai 5 bulan. Bunyi yang diproduksi pada usia ini merupakan respon atas tindakan dari 
Vol. 1, No. 1 (2022)

DOI; https://doi.org/10.37680/linguafranca.v1i1.1220

sang ibu. Bunyi utuh akan diprosuksi anak pada usia 4 sampai 7 bulan. Bunyi yang diprosuksi tidak hanya vokal dan konsonan melaikan banyak variasi yang menyertainya. Sampai pada anak akan memproduksi bunyi yang berulang dari bunyi vokal maupun konsonan pada usia 6 sampai 12 bulan.

Selain tahapan berbahasa, ada pula fase pembetukan kata pada seorang anak. Biasanya tahap itu diberi nama tahap satu kata, dua kata, dan banyak kata. Ketika anak berusia 12 sampai 18 bulan, maka tahap yang dilalui adalah tahap satu kata. Pada tahap ini seorang anak akan memproduksi satu kata yang bermakna dan memiliki arti. Satu kata yang diprosuksi tersebut mewakili satu atau lebih dari satu frasa. Tahapan satu kata ini biasa disebut sebagai tahap holofrafis.

Saat anak berusia 18 sampai 24 bulan, maka tahap yang dilaluinya adalah tahap dua kata. Perkembagan kosakata maupun gramatika akan berkembang cepat pada tahap ini. Anak akan mulai memproduksi dua kata dalam berbicara. Tuturan yang diproduksi juga bersifat telegrafik, tuturan yang diprosuksi si anak hanya kata yang penting saja seperti kata kerja, sifat, taupun kata benda.

Ketika anak berusia 3 sampai tahun, maka tahap yang dilalui adalah tahap banyak kata. Pada tahap ini tuturan yang diproduksi anak akan lebih banyak dan lebih panjang, bahasa yang diprosuksi juga lebih teratur. Sedangkan pada usia 5 sampai 6 tahun bahasa yang diproduksi anak telah menyerupai tuturan orang dewasa.

Pemerolehan bahsa kedua adalah kajian tentang bagaimana bahasa kedua diperoleh dan dipelajari oleh seseorang. Bahasa non primer atau B2 tersebut disebut dengan bahasa kedua. Bahasa kedua tersebut tidak dibatasi oleh bahasa asing, daerah, ataupun nasional (Laurence N, 2000).

Analisis Error (AE) atau analisis kesalahan berbahasa adalah kajian linguistik yang mempelajari tentang kemampuan seseorang dalam memperoleh dan mempelajari bahasa asing atau bahasa kedua (Corder, 1967). Misalnya, pada pengucapan, kosakata, dan struktur kalimatnya. Dalam proses pembelajarannya, seseorang menggunakan fitur bahasa pertama B1 ke Bahasa kedua B2.

Kajian terkait pemerolehan bahasa kedua menunjukkan hasil yang dapat membantu untuk mengetahui permasalahan terkait kebahasaan. Penelitian dengan judul Korelasi Pemerolehan Bahasa terhadap Keterampilan Berbicara Bahasa Arab Perspektif Neurolinguistik (Studi Kasus Mahasiswa Pendidikan Bahasa Arab Unja), memperoleh hasil bahwa pemerolehan bahasa yang dimiliki saling berhubungan dengan keterampilannya dalam berbicara. Hal tersebut juga melihat dari sisi kompetensi leksikosemantik dan makrostruktur dalam keterampilan pragmatik (Zefriando, 2021). Penelitian dengan judul Model Pemerolehan Bahasa Arab sebagai Bahasa Asing pada Peserta Didik Non-Native 
Vol. 1, No. 1 (2022)

DOI; https://doi.org/10.37680/linguafranca.v1i1.1220

Speaker (Kajian Teori Psikolinguistik), yang menunjukkan hasil bahwa segala sesuatu yang berkaitan dengan keterampilan berbahasa membutuhkan latihan dalam penguatan dan pengulangan bahasa sebagai proses pemerolehan bahasa kedua (Huda, 2017).

Penelitian dengan judul Pengenalan Bahasa Arab untuk Anak Sejak Dini, yang mengungkapkan bahwa beberapa faktor yang mempengaruhi pemerolehan bahasa asing B2 pada anak adalah motivasi, usia, penyajian, bahasa pertama, dan lingkungannya. Dalam penelitiannya juga menegaskan terkait pentingnya pengenalan bahasa kedua kepada anak usia dini karena membawa dampak yang baik bagi anak, seperti menambah intelektualitas diri, keterampilan bidang akademik, berbahasa, bersosial, serta memiliki kesiapan di dunia pergaulan dengan berbagai bahasa dan budaya (Faridah, 2017). Penelitian lainnya dengan judul Pemerolehan Fonologi Bahasa Arab Anak Usia 12 Tahun di MTs Islam Ngruki Sukoharjo (Tinjauan Psikolinguistik), menunjukkan hasil bahwa faktor pendukung keberhasilan penguasaan bahasa tataran fonologi anak seperti faktor keluarga, sikap, motivasi, bakat, minat, kesehatan, usia, kecerdasan, dan lingkungan. Faktor lingukangan terbagi menjadi lingkungan formal dan informal. Lingkungan formal berperan penting dalam penguasaan tata bahasa fonetik, sedangkan lingkungan informal berperan penting dalam penguasaan kosakata (Faiqoh, 2014).

Pada proses pemerolehan bahasa asing melibatkan dua proses, yaitu proses reseptif dan produktif. Hal tersebut sesuai dengan penelitian dengan judul Akuisisi Bahasa Kedua pada Anak Usia 4-5 Tahun di RA Manafiul Ulum Kudus. Hasil penelitiannya menunjukkan bahwa proses reseptif sangat berkaitan dengan kemampuan dalam pemahaman, sedangkan proses produktif erat kaitannya dengan penerbitan kalimat. Dengan demikian metode dan teknik yang dikembangkan dalam hasil penelitian adalah metode atraktif seperti bercerita, mendongeng, berkebun, dan berbagai permainan bahasa (Annas, 2019).

Bahasa Arab merupakan bahasa asing bagi pembelajar bahasa kedua. Fenomena yang berkaitan dengan kajian tersebut cukup terasakan. Sedangkan kajian penelitian yang berkaitan dengan pemerolehan bahasa arab di Pondok Modern Arrisalah Ponorogo belum ada yang melakukannya. Padahal hal tersebut sangat penting untuk mengetahui permasalahan terkait kebahasaan Arab anak di wilayah tersebut. Berdasarkan hal tersebut, peneliti tertarik untuk mengkaji tentang bagaimana pemerolehan Bahasa Arab untuk anak usia 4 sampai 8 tahun pada tingkat PIAUD dan SD di Pondok Modern Arrisalah Ponorogo.

Kajian ini ditekankan pada pemerolehan Bahasa Arab. Fenomena terkait pemerolehan Bahasa Arab dianggap penting bagi peneliti untuk mengetahui tingkat kesetiaan dan kesadaran anak di Pondok Modern Arrisalah Ponorogo dalam menggunakan Bahasa Arab. Dengan penelitian ini, dapat diketahui bagaimana tanggung jawab anak dalam memelihara Bahasa Arab. 
Vol. 1, No. 1 (2022)

DOI; https://doi.org/10.37680/linguafranca.v1i1.1220

Jenis penelitian pada penelitian ini adalah deskriptif kualitatif. Teknik simak, rekam, dan catat menjadi beberapa alat yang digunakan dalam teknik pengumpulan data. Penelitian ini juga menggunakan teknik analisis data model interaktif Miles dan Huberman. Objek kajian dalam penelitian ini dilakukan terhadap anak-anak usia 4 hingga 8 tahun tingkat PIAUD sampai dengan tingkat SD di Pondok Modern Arrisalah Ponorogo. Tujuannya agar pengawasan terhadap perkembangan Bahasa Arab yang menjadi bahasa agamanya (Islam) terus berjalan sehingga meningkatkan kepandaian anak dalam berbahasa Arab.

\section{PEMBAHASAN}

Pemerolehan bahasa biasa digunakan untuk padanan kata dalam Bahasa Inggris. Pemerolehan bahasa pada anak tentu berbeda dengan penguasaan bahasa pada pembelajar. Pemerolehan bahasa pada anak biasanya lebih bersifat natural, sedangkan pada pembelajar biasanya dipengaruhi oleh proses belajar itu sendiri. Hal tersebut juga berbeda dengan proses pemerolehan bahasa dengan proses pembelajaran bahasa. Proses pemerolehan bahasa asing pada orang dewasa sama halnya dengan cara anak-anak mengembangkan kemampuan bahasa pertama mereka (Jumhana, 2014). Kajian tentang pemerolehan bahasa kedua bisa dipahami sebagai kajian ilmu interdisipliner yang menungkapkan beberapa faktor di luar bahasa, seperti faktor psikis maupun faktor sosial. Faktor yang berkaitan tersebut merupakan ilmu interdisipliner seperti psikolinguistik, sosiolinguistik, maupun neurolinguistik. Proses pembelajaran bahasa berbeda dengan pemerolehan bahasa. Pemerolehan bahasa biasanya diperoleh terlebih dulu sebelum melakuakan proses pemerolehan bahasa kedua atau bahasa asing (Jumhana, 2014).

Pemerolehan bahasa terjadi secara tidak sengaja dan tiba-tiba. Biasanya muncul sebagai permulaan yang gradual dari motorik, kognitif, sosial, dan pralingusitik. Pada tahap pembelajar, manusia akan dihadapkan pada pemerolehan dan penguasaan bahasa kedua atau bahasa asing. Hal tersebut akan cenderung dilakukan melalui tahap pembelajaran. Namun, dalam proses pembelajaran berbahasa terjadi proses pemerolehan bahasa asing atau bahasa kedua pada saat seseorang tersebut mempelajarinya. Oleh karena itu, akan muncul istilah tentang pemerolehan bahasa kedua. Hal tersebut tentu berbeda dengan proses pembelajaran bahasa, meskipun pada proses pemerolehan bahasa asing atau bahasa kedua dimulai dari proses pembelajaran bahasa.

Pada tahap pemerolehan bahasa asing atau bahasa kedua, tentu didasarkan pada teori-teori tentang pemerolehan bahasa pertama. Perkembangan social anak sangat dipengaruhi oleh proses pemerolehan bahasa pertamanya. Hal tersebut juga berhubungan dengan bagaimana identitas social anak terbentuk, sehingga proses pemerolehan bahasa 
Vol. 1, No. 1 (2022)

DOI; https://doi.org/10.37680/linguafranca.v1i1.1220

pertama akan membentuk karakter dan identitas seorang anak yang akan tumbuh dan berkembang di lingkungan masyarakat.

Perbedaan terkait pemerolehan bahasa dan pembelajaran bahasa oleh Mahmud didefinisikan bahwa pemerolehan bahasa lebih ditekankan pada penguasaan bahasa oleh seorang anak terjadi secara tidak disengaja, sedangkan pembelajaran bahasa lebih ditekankan pada penguasaan bahasa yang terjadi secara disengaja (Mahmud \& Idham, 2019).

Studi terkait pemerolehan bahasa biasanya mencakup pemerolehan bunyi atau fonologi, pembentukan kata atau morfologi, sintaksis atau tata bahasa, dan semantik atau pemaknaan. Pemerolehan fonologi merupakan pemerolehan yang utama dan tergolong sangat penting. Hal itu karena dapat memengaruhi pemerolehan-pemerolehan bahasa pada bidang lainnya (Wijayanti, 2021). Pemerolehan bahasa biasanya digunakan untuk membahas penguasaan bahasa pertama dengan penguasaan bahasa kedua, di mana kedua proses tersebut terjadi karena faktor yang berbeda. Pemerolehan pada anak-anak biasanya dipengaruhi karena faktor lingkungan secara non formal, sedangkan pada orang dewasa pemerolehan tersebut terjadi karena faktor formal. Pembetulan dari pemerolehan bahasa anak dilakukan oleh lingkungan non formal, sedangkan pada orang dewasa pembetulan akan dilakukan dengan cara berlatih ulang (Agusalim \& Suryanti, 2021).

Bahasa Arab merupakan bahasa yang digunakan pada lingungan bilingual. Salah satu lembaga pendidikan yang menerapkan sistem bilingual yaitu Pondok Modern Arrisalah Ponorogo. Berikut akan dijelaskan terkait pemerolehan Bahasa Arab anak di Pondok Modern Arrisalah Ponorogo.

\section{Temuan Kasus 1}

Narasumber pada penelitian kasus 1 adalah seorang anak laki-laki bernama Jamalludin Ahmad, atau biasa dipanggil Jamal. Jamal berusia 4 tahun, ia tinggal di Desa Josari, Dusun Kebon, Kecamatan Jetis, Kabupaten Ponorogo. la menempuh Pendidikan play group di Kelompok Bermain Modern Arrisalah (KBIA). Dalam kehidupannya sehari-hari Jamal menggunakan bahasa Indonesia, baik Bersama keluarga maupun teman sepermainannya.

Pemerolehan Bahasa Arab oleh Jamal dapat dianalisis dari kalimat "Bismiyyāhhiyyohmāniyyahīm. Allāhumma innī audubika minal hubusi wal habaisi". Jika di petakan, kesalahan narasumber dalam pelafalan dapat dilihat pada tabel berikut.

Tabel 1. Pemerolehan bahasa kasus 1

\begin{tabular}{lll}
\hline Lafal Narasumber & \multicolumn{1}{c}{ Lafal Asli } & \multicolumn{2}{c}{ Pemerolehan Bunyi } \\
\hline Bismiyyāh & Bismillāh & Pemerolehan sudah baik, \\
& & hanya saja terdapat \\
\hline
\end{tabular}


Vol. 1, No. 1 (2022)

DOI; https://doi.org/10.37680/linguafranca.v1i1.1220

\begin{tabular}{|c|c|c|}
\hline & & $\begin{array}{l}\text { perubahan bunyi fonem } \\
\text { " } r \text { " menjadi " } y \text { " }\end{array}$ \\
\hline Hiyyahmān & Hirrahmān & $\begin{array}{l}\text { Pemerolehan sudah baik, } \\
\text { hanya saja terdapat } \\
\text { perubahan bunyi fonem } \\
\text { "r" menjadi " } y \text { " }\end{array}$ \\
\hline Niyyahīm & Nirrahīm & $\begin{array}{l}\text { Pemerolehan sudah baik, } \\
\text { hanya saja terdapat } \\
\text { perubahan bunyi fonem } \\
\text { " } r \text { " menjadi fonem " } y \text { " }\end{array}$ \\
\hline Allūhumma & Allāhumma & $\begin{array}{l}\text { Pemerolehan sudah baik, } \\
\text { hanya saja terdapat } \\
\text { perubahan bunyi fonem } \\
\text { "a" menjadi fonem "u" }\end{array}$ \\
\hline Audubika & $A^{\prime}$ ūdubika & $\begin{array}{l}\text { Pemerolehan sudah baik, } \\
\text { hanya saja terdapat } \\
\text { perubahan bunyi fonem " } \\
\text { 'ū" menjadi "u" dan } \\
\text { mengalami pemotongan } \\
\text { panjang bacaan. }\end{array}$ \\
\hline Minal hubusi & Minal khubusii & $\begin{array}{l}\text { Pemerolehan sudah baik, } \\
\text { hanya saja terdapat } \\
\text { perubahan bunyi fonem } \\
\text { "kh" menjadi fonem " } h \text { " } \\
\text { dan perubahan fonem "s" } \\
\text { menjadi "s" }\end{array}$ \\
\hline Wal habaisi & Wal khabāisii & $\begin{array}{l}\text { Pemerolehan sudah baik, } \\
\text { hanya saja pemotongan } \\
\text { panjang bacaan "bā", } \\
\text { perubahan fonem "kh" } \\
\text { menjadi fonem " } \mathrm{h} \text { ", dan } \\
\text { perubahan fonem "s" } \\
\text { menjadi "s" }\end{array}$ \\
\hline
\end{tabular}

Produksi kalimat ungkapan narasumber pada kata "bismiyyāh" terdapat perubahan fonem " $y$ " yang tidak sesuai deangan ungkapan sebenarnya. Hal itu karena pada bacaan dan tulisan yang aslinya pada kata "bismillāh" tidak memakai kata ya fathah pada bagian huruf 
Vol. 1, No. 1 (2022)

DOI; https://doi.org/10.37680/linguafranca.v1i1.1220

tengah. Pemerolehan bunyi yang sama juga terjadi pada kata "hiyyohmān dan niyyohïm" di mana terdapat perubahan fonem " $y a$ " pada tengah kata, sehingga kata tersebut tidak sesuai dengan bacaan dan tulisan aslinya. Pemerolehan bunyi yang sama juga terdapat pada lafadz "allūhumma" dikarenakan perubahan fonem " $a$ " menjadi fonem " $u$ ". Terdapat pemerolehan bunyi yang kurang tepat pada lafadz "minal hubusi dikarenakan penggantian fonem " $\dot{s}$ " dengan " $s$ " dan wal hobaisi" terdapat perubahan fonem " $k h$ " menjadi fonem "ha", serta kata "hobais" terdapat perubahan lafal "is" menjadi fonem "is" Hal ini mengakibatkan tidak adanya makna pada lafadz-lafadz tersebut karena penguasaan bunyi yang kurang tepat.

\section{Temuan Kasus 2}

Narasumber selanjutnya dalam penelitian ini adalah seorang anak laki-laki bernama Danish Daffa Nur Pratama, biasa dipanggil Daffa. Daffa berusia 5 tahun tinggal di Dukuh Bulu, Desa Crabak, Kecamatan Slahung, Kabupaten Ponorogo. Lingkungan tempat tinggalnya ada di sekitar Pondok Modern Arrisalah Program Internasional. Daffa dalam kesehariannya menggunakan Bahasa Indonesia dan Bahasa Jawa. Ia menempuh pendidikan di Taman Kanakkanak Islam Arrisalah (TKIA). Pemerolehan Bahasa Arab Daffa dapat diperhatian pada kalimat "Allāhumma bariklanā pimā rajaktana wākinā adabannar". Pemetan kesalahannya dapat dilihat di tabel berikut.

Tabel 2. Pemerolehan bahasa kasus 2

\begin{tabular}{|c|c|c|}
\hline Lafal Narasumber & Lafal Asli & Pemerolehan Bunyi \\
\hline \multirow[t]{3}{*}{ Bariklan̄ā } & \multirow[t]{3}{*}{ Bārik lanā } & Pemerolehan sudah baik, hanya \\
\hline & & saja terdapat pemotongan \\
\hline & & panjang bacaan pada lafal " $b \bar{a}$ " \\
\hline \multirow[t]{5}{*}{ Pimā } & \multirow[t]{5}{*}{ Fimā } & Pemerolehan sudah baik, hanya \\
\hline & & saja terdapat pemotongan \\
\hline & & panjang bacaan "fi" dan \\
\hline & & perubahan fonem " $f$ " menjadi \\
\hline & & fonem " $p$ " \\
\hline \multirow[t]{6}{*}{ Rajaktana } & \multirow[t]{6}{*}{ Razaqtanā } & Pemerolehan sudah baik, hanya \\
\hline & & saja terdapat perubahan bunyi \\
\hline & & fonem " $z$ " menjadi fonem " $j$ ", \\
\hline & & perubahan fonem " $q$ " menjadi \\
\hline & & fonem " $k$ ", dan pemotongan \\
\hline & & panjang bacaan "nā" \\
\hline \multirow[t]{2}{*}{ Wākinā } & \multirow[t]{2}{*}{ Wa qinā } & Pemerolehan sudah baik, hanya \\
\hline & & saja terdapat pemanjangan lafal \\
\hline
\end{tabular}


Vol. 1, No. 1 (2022)

DOI; https://doi.org/10.37680/linguafranca.v1i1.1220

\begin{tabular}{|c|c|c|}
\hline & & $\begin{array}{l}\text { " } w a \text { " dan perubahan fonem " } q \text { " } \\
\text { menjadi fonem " } k \text { " }\end{array}$ \\
\hline \multirow{4}{*}{ 'Adabannar } & \multirow{4}{*}{ 'AŻābannār } & Pemerolehan sudah baik, hanya \\
\hline & & $\begin{array}{l}\text { saja terdapat perubahan bunyi } \\
\text { fonem " } Z \text { " menjadi fonem " } d \text { " }\end{array}$ \\
\hline & & dan pemotongan panjang \\
\hline & & bacaan pada kata "Żā" dan "nār" \\
\hline
\end{tabular}

Produksi kalimat ungkapan narasumber pada kata "bariklanā" terdapat pemotongan panjang bacaan pada " $b a$ " di awal bacaan. Pemerolehan bunyi selanjutnya terdapat pada lafadz "pimā", yakni adanya perubahan bunyi " $f$ " kasroh menjadi " $p$ " kasroh, dengan lafadz asli "fïmā". Adanya pemanjangan kata "wa" pada lafadz "wakinaa" serta perubahan bunyi "qi" menjadi "ki". Hal itu karena tidak sesuai dengan bacaan dan tulisan aslinya "wa qinā". Pada lafadz "adabannar" terdapat perubahan fonem " $Z$ " menjadi fonem " $d$ " dari kata asli "'aŻābannār", serta adanya pemotongan panjang bacaan pada kata "Ż̄̄" dan "nār". Hal itu mengakibatkan pemaknaan yang berbeda karena masih kurangnya penguasaan fonologi pada anak.

\section{Temuan Kasus 3}

Temuan penelitian selanjutnya adalah seorang anak perempuan bernama Aisha Syifa Aalinarrohman yang biasa dipanggil Aisha. Aisha adalah anak berusia 6 tahun yang tinggal di Desa Janti, Kecamatan Slahung. Dalam kesehariannya di rumah menggunakan Bahasa Jawa untuk berkomunikasi dengan lingkungan keluarganya, sedangkan di sekolah menggunakan Bahasa Indonesia. Aisha adalah salah satu siswi TK Islam Arrisalah.

Pemerolehan Bahasa Arab Aisha dapat diperhatikan pada kalimat "bismillāhhillahmānillahīm qul huwallāhu ahad allāhu așșhamad lam yalid wa lam yūlad wa lam yakullahū kufuwan ahad". Jika di petakan, kesalahan narasumber dalam pelafalan dapat dilihat pada tabel berikut.

Tabel 3. Pemerolehan bahasa kasus 3

\begin{tabular}{cll}
\hline Lafal Narasumber & \multicolumn{1}{c}{ Lafal Asli } & \multicolumn{1}{c}{ Pemerolehan Bunyi } \\
\hline bismillahillahmaanillahim & Bismillahirrahmaanirrahim & Seluruh pemerolehan \\
& sudah baik kecuali \\
& perubahan fonem " $r$ " \\
& menjadi fonem "l" \\
\hline
\end{tabular}

Apabila diperhatikan lafal narasumber hanya terjadi sedikit kesalahan yakni pada pelafalan fonem " $r$ " pada kalimat yg seharusnya bismillāhirrahmānirrahìm menjadi fonem "l". Untuk lafal narasumber yang lainnya terdengar fasih dan benar menurut kaidah pelafalan Bahasa Arab. 
Vol. 1, No. 1 (2022)

DOI; https://doi.org/10.37680/linguafranca.v1i1.1220

\section{Temuan Kasus 4}

Narasumber pada temuan kasus 4 adalah seorang anak laki-laki bernama Abdullah Rasyiqul Abid yang biasa dipanggil Abid. Abid berusia 7 tahun yang tinggal di Desa Bediwetan, Kecamatan Bungkal, Kabupaten Ponorogo. la bersekolah di Sekolah Dasar Islam Arrisalah dan sekarang duduk di kelas satu. Sehari-harinya ia menggunakan Bahasa Jawa untuk berkomunikasi dengan orang tua dan teman-teman di lingkungan tempat tinggalnya. Sedangkan Bahasa Indonesia digunakan untuk berkomunikasi dengan teman-teman dan guru-gurunya di lingkungan sekolah.

Pemerolehan Bahasa Arab Abid dapat diperhatikan pada kalimat "Al amdulillāhilladī adhaba anil adāti wa afānı̈". Jika dipetakan, kesalahan narasumber dalam pelafalan dapat dilihat pada tabel berikut.

Tabel 4. Pemerolehan bahasa kasus 4

\begin{tabular}{|c|c|c|}
\hline Lafal Narasumber & Lafal Asli & Pemerolehan Bunyi \\
\hline \multirow[t]{6}{*}{ Al amdulillāhilladī } & Alhamdulillāhillażì & Pemerolehan sudah baik, \\
\hline & & hanya saja terdapat \\
\hline & & penghilangan fonem " $h$ " pada \\
\hline & & lafal "alhamdu" dan \\
\hline & & perubahan fonem " $\dot{Z} \vec{l}$ " menjadi \\
\hline & & "dī" \\
\hline \multirow[t]{4}{*}{ Adhaba } & AŻhaba & Pemerolehan sudah baik, \\
\hline & & hanya saja terdapat \\
\hline & & perubahan fonem "Ż" menjadi \\
\hline & & fonem " $d$ " \\
\hline \multirow[t]{4}{*}{ Anil } & 'anil & Pemerolehan sudah baik, \\
\hline & & hanya saja terdapat \\
\hline & & perubahan bunyi fonem \\
\hline & & "'a:áin" menjadi fonem " $a$ " \\
\hline \multirow[t]{5}{*}{ Adaati } & $\mathrm{A} \dot{Z} \bar{a}$ & Pemerolehan sudah baik, \\
\hline & & hanya saja terdapat \\
\hline & & perubahan bunyi fonem "Żं̄" \\
\hline & & menjadi $\quad d \bar{a} " \quad$ dan \\
\hline & & penambahan kata "ti" \\
\hline \multirow[t]{4}{*}{ Wa afānī } & Wa 'afānī & Pemerolehan sudah baik, \\
\hline & & hanya saja terdapat \\
\hline & & perubahan bunyi fonem \\
\hline & & “'a:'ain" menjadi “a” \\
\hline
\end{tabular}


Vol. 1, No. 1 (2022)

DOI; https://doi.org/10.37680/linguafranca.v1i1.1220

Terdapat pemerolehan bunyi yang kurang tepat pada pengucapan "alhamdulillāh" yaitu pengurangan fonem " $h$ " dan allażì menjadi alladī, serta perubahan lafal " $\dot{Z} \bar{l}$ " menjadi "di". Selain itu terdapat perubahan fonem " $Z$ " menjadi " $d$ " pada kalimat yang seharusnya berbunyi ażhaba dan perubahan fonem "'a:'ain" dalam kalimat 'anil dan 'afāni, serta perubahan fonem " $Z$ " menjadi " $d$ " pada lafal $a \dot{Z} \bar{a}$ dan adanya penambahan kata "ti".

\section{Temuan Kasus 5}

Narasumber dalam temuan kasus 5 ini adalah seorang anak perempuan bernama Fatiya Ainul Fadhilah, biasa dipanggil Fatiya. Fatiya berusia 8 tahun berasal dari Desa Ngumpul, Dusun Ngumpul, Kecamatan Balong, Kabupaten Ponorogo. la menempuh pendidikan sekolah dasar di Pondok Arrisalah sebagai salah satu siswi kelas 2 SD. Sehariharinya Fatiya menggunakan Bahasa Indonesia untuk berinteraksi dengan keluarga dan teman-teman di lingkungannya. Fatiya juga bermukim di Pondok Arrisalah.

Pemerolehan Bahasa Arab Fatiya dapat diperhatikan pada kalimat "Tabbat yada abi lahabiwwatab, ma agna 'anhu māluhū wa mā kasab, sayașla nāran Żāta lahab, wa'imra'atuh, ḥammālata al-ḥatab, fi jīdihā ḥablummimmasad" pada tabel berikut.

Tabel 5. Pemerolehan bahasa kasus 5

\begin{tabular}{lll}
\hline \multicolumn{1}{c}{ Lafal Narasumber } & Lafal Asli & \multicolumn{2}{c}{ Pemerolehan Bunyi } \\
\hline Yada & Yadā & $\begin{array}{l}\text { Pemerolehan sudah baik, } \\
\text { hanya saja terdapat } \\
\end{array}$ \\
& Māagna & $\begin{array}{l}\text { pemotongan panjang } \\
\text { bacaan pada lafal "dā" }\end{array}$ \\
\hline Ma agna & $\begin{array}{l}\text { Pemerolehan sudah baik, } \\
\text { hanya saja terdapat }\end{array}$ \\
& pemotongan panjang \\
& bacaan pada lafal "mā"
\end{tabular}

Produksi kalimat ungkapan narasumber pada kata "Yada" terdapat pemotongan panjang bacaan "dā" yang seharusnya adalah "Yadā" dibaca panjang. Pemerolehan yang kurang tepat juga pada lafal "mā" yang mengalami pemotongan panjang bacaan. Dari sini dapat disimpulkan bahwa kesalahan narasumber hanya terletak pada panjang pendek saja.

\section{PENUTUP}

Bedasarkan hasil penelitian dan pembahasan yang telah dipaparkan, maka dapat ditarik kesimpulan bahwa pemerolehan bahasa lebih ditekankan pada penguasaan bahasa oleh seorang anak yang terjadi secara tidak disengaja, sedangkan pembelajaran bahasa lebih ditekankan pada penguasaan bahasa yang terjadi secara disengaja. Pemerolehan fonologi Bahasa Arab anak usia 4 sampai 8 tahun di Pondok Arrisalah Slahung Ponorogo belum 
Vol. 1, No. 1 (2022)

DOI; https://doi.org/10.37680/linguafranca.v1i1.1220

sepenuhnya sempura. Hal itu karena masih banyak pemerolehan yang kurang tepat, seperti pelafalan bunyi yang salah, penabahan bunyi yang tidak perlu, dan pengucapan panjang pendeknya huruf yang masih salah.

Pada umunya penelitian ini menemukan pola yang hamper mirip terkait dengan penelitian pemerolehan Bahasa Arab di kalangan anak. Meskipun demikian, penelitian ini belum sangat dalam dan jauh menelisik kehidupan sosiologis dan antropologis kebahasaan mereka. Oleh sebab itu, peneliti merekomendasikan agar penelitian terkait sosiolinguistik dan antropolinguistik Bahasa Arab pada usia dini perlu terus dilakukan.

\section{BIBLIOGRAFI}

Agusalim, \& Suryanti. (2021). Konsep Pembelajarn Bahas Indonesia Kelas Rendah. CV Bintang Surya Madani.

Annas, A. (2019). AKUISISI BAHASA KEDUA PADA ANAK USIA 4-5 TAHUN DI RA MANAFIUL ULUM KUDUS. Journal ThufuLa, 7(2).

Chaer, A. (2003). Psikolinguistik: Kajian Teoritik. Rineka Cipta.

Corder, S. P. (1967). The significance of learners' errors. International Review of Applied Linguistics, 5, 160-170.

Faiqoh, M. D. (2014). PEMEROLEHAN FONOLOGI BAHASA ARAB ANAK USIA 12 TAHUN DI MTS ISLAM NGRUKI SUKOHARJO (Tinjauan Psikolinguistik). Jurnal CMES, VII(1).

Faridah, L. U. (2017). Pengenalan Bahasa Arab Untuk Anak Sejak Dini. Prosiding Konferensi Nasional Bahasa Arab III, 411-419.

Fatmawati, S. R. (2015). Pemerolehan Bahasa Pertama Anak Menurut Tinjauan Psikolinguistik. Lentera, XVIII(1), 63-75.

Huda, N. (2017). Model Pemerolehan Bahasa Arab Sebagai Bahasa Asing Pada Peserta Didik Non-Native Speaker (Kajian Teori Psikolinguistik). Nidhomul Haq: Jurnal Manajemen Pendidikan Is/am, 2(2), 84-94. https://doi.org/10.31538/nidhomulhaq.v2i2.32

Izan, A. (2011). Metodologi Pembelajaran Bahasa Arab. Humaniora.

Jumhana, N. (2014). Pemerolehan Bahasa Pada Anak. Al-Ittijah Jurnal Keilmuan Dan Kependidikan Bahasa Arab, 6(2), 109-128.

Laurence N, B. (2000). The Benefits of Second Language Acquisition and Teaching for Indigenous Language Educators. Journal of American Indian Education, 39(3), 14-16.

Mahmud, S., \& Idham, M. (2019). Teori Belajar Bahasa. Syiah Kuala University.

Syahid, A. H. (2014). Kepribadian EkstrovertIntrovert dan Pemerolehan Bahasa Kedua Perspektif Psikolinguistik pada Santri Pondok Modern. AlQalam Jurnal Kajian Keislaman, 31(2), 399-426.

Tarigan, H. G. (2011). Pengajaran Pemerolehan Bahasa. Angkasa. 
Vol. 1, No. 1 (2022)

DOI; https://doi.org/10.37680/linguafranca.v1i1.1220

Wijayanti, L. M. (2021). Penguasaan Fonologi dalam Pemerolehan Bahasa : Studi Kasus Anak Usia 1. 5 Mastery Of Phonology In Language Acquisition: A Case Study Of Child Aged 1. 5 Institut Agama Islam Sunan Giri , Ponorogo dianggap universal dan otonom tanpa melihat fungsinya seb. Absorbent Mind, 1(1), 12-24.

Wiziack, J. C., \& dos Santos, V. M. P. D. (2021). Evaluating an integrated cognitive competencies model to enhance teachers' application of technology in large-scale educational contexts. Heliyon, 7(1). https://doi.org/10.1016/j.heliyon.2021.e05928

Zefriando, G. (2021). Korelasi Pemerolehan Bahasa Terhadap Keterampilan Berbicara Bahasa Arab Perspektif Neurolinguistik (Studi Kasus Mahasiswa Pendidikan Bahasa Arab Unja). Ad-Dhuha: Jurnal Pendidikan Bahasa Arab Dan Budaya Islam, 2(01), 1-11. https://kbbi.kemdikbud.go.id/, 